\title{
Back To Basics: Algebraic Foundations Of The Statement Of Cash Flows
}

Donald T. Joyner, Norfolk State University, USA

Jean-Marie Banatte, Norfolk State University, USA

V. Reddy Dondeti, Norfolk State University, USA

\begin{abstract}
The indirect method for preparing the statement of cash flows, as described in many standard textbooks, involves an item-by-item approach, telling you to add to or subtract from the net income, the increases or decreases in the balance sheet items, such as accounts payable or accounts receivable. Many business students, especially at the undergraduate level, find these black-box-rules confusing. In recent years, several articles have appeared in the accounting literature, exploring the link between the algebraic foundations and the enumeration of items in the statement of cash flows. In this paper, an explanation is provided, through an analysis of the basic algebraic equation of the balance sheet, for the black-box-rules of the indirect method in a simple and concise manner.
\end{abstract}

Keywords: Statement of Cash Flows; Indirect Method; Algebraic Foundation; Accounting Equation

\section{INTRODUCTION}

f preparation of the Statement of Cash Flows (SCF) by the indirect method, as described in many standard textbooks such as Kieso et al. (2012), a separate rule is prescribed for an increase or decrease in an item of the balance sheet. For example, one of the rules tells you to add the decreases in current assets, such as Accounts Receivable and Inventories, to the net income, but subtract any increases. In contrast, the increases in current liabilities, such as Accounts Payable and Accrued Expenses Payable, are added to the net income, but any decreases are subtracted. Further, you add the depreciation and any losses from the sale of fixed assets and subtract the corresponding gains from the net income.

Many business students, especially at the undergraduate level, find these black-box-rules confusing. In recent years, alternative approaches based on the algebraic foundations of accounting have appeared in literature with the goal of explaining the item-by-item enumeration rules of the indirect method. Some rudimentary ideas linking the algebraic equations of the balance sheet and the preparation of the SCF are presented in Chen and Dondeti (2000). The detailed nature of the algebraic relations and their role in the preparation of the SCF are described in Rai (2003) and Chen et al. (2009). Pedagogical approaches aimed at helping the students improve their understanding of the different steps involved in the preparation of the SCF are discussed in O'Bryan et al. (2000), Laux (2009), Wang (2010), and Cecil et al. (2011). In this paper, the goal is to supplement the recent pedagogical approaches to the preparation of the SCF. With the aid of the basic algebraic equation of the balance sheet, an explanation is provided for the item-by-item enumeration rules of the indirect method in a simple and concise manner. This approach will not only add to the existing literature on the link between the algebraic foundations of accounting and the black-box-rules of the indirect method, but will also help the instructors teach more effectively and the students grasp more clearly the steps involved in the preparation of statement of cash flows by the indirect method.

\section{ALGEBRAIC REPRESENTATION OF THE BALANCE SHEET}

The fundamental relation among the items in the balance sheet is given by the following equation:

Assets $=$ Liabilities + Stockholders` Equity 
If each item in the balance sheet is represented by an algebraic symbol, it will lead to a mathematical equation. Suppose the data given in Table 1 represents the balance sheet of the XYZ Company at the end of the year 2011.

Table 1: The XYZ Company - Balance Sheet at End of 2011

\begin{tabular}{|l|c|c|c|}
\hline \multicolumn{1}{|c|}{ Assets } & Amount \$ & Liabilities \& Equity & Amount \$ \\
\hline Cash (C) & 63,000 & Accounts Payable (P) & 57,000 \\
\hline Accounts Receivable (R) & 59,000 & & \\
\hline Inventories (V) & 28,000 & & \\
\hline Land (D) & 95,000 & Bonds Payable (B) & 265,000 \\
\hline Buildings (G) & 215,000 & Common Stock (S) & 318,000 \\
\hline Equipment (Q) & 340,000 & Total (Z) & 160,000 \\
\hline Total (Z) & 800,000 & 800,000 \\
\hline
\end{tabular}

Let each letter in the parenthesis denote the corresponding balance sheet item in Table 1. The resulting algebraic equation is:

$\mathrm{C}+\mathrm{R}+\mathrm{V}+\mathrm{D}+\mathrm{G}+\mathrm{Q}=\mathrm{P}+\mathrm{B}+\mathrm{S}+\mathrm{T}$

The basic property of any algebraic equation, such as (2), is that the sum of the variables on the Left-HandSide (LHS) must always be equal to the sum of the variables on the Right-Hand-Side (RHS). An additional condition, in case of the balance-sheet items in Equation (2), is that any variable can be zero or positive but never negative. An interesting observation is that a change in one variable on one side may lead to changes in just one or many other variables on either side.

\section{CASH FLOWS FROM INVESTING ACTIVITIES}

Instead of starting with operating activities, suppose that you begin with investing activities in the preparation of the SCF. There is an advantage in doing it this way, as explained later. Companies raise the funds needed to buy the assets used in their operations through the issue of bonds and stocks. Buying and selling of land, buildings, and equipment are referred to as investing activities. Suppose that at the beginning of the year, a building with a book value of $\$ 70,000$ was sold for $\$ 80,000$ and equipment with a book value of $\$ 110,000$ was sold for $\$ 50,000$. The company also raised cash in the amount of $\$ 100,000$ by issuing common stock. Then it bought new equipment worth $\$ 220,000$. You may think of the book value as the amount of money you expect to receive when you sell an asset. However, you may get more or less for the asset depending on condition of the asset and market demand. Assume that no land was bought or sold. Then, the cash flows from the investing activities can be described as:

Cash Flows from Investing Activities:

Book value (or expected amount of cash) of buildings sold: $\quad \$ 70,000$

Gain from the sale of the buildings: $\quad \underline{10,000}$

Actual amount of cash from sale of buildings:

$\underline{10,000} \$ 80,000$

Book value (or expected amount of cash) of equipment sold: $\quad \$ 110,000$

Loss from sale of equipment:

Actual amount of cash from the sale of equipment: $\quad \$ 50,000$

Purchase of new equipment: $\quad(\$ 220,000)$

Net cash generated by investing activities $\quad(\$ 90,000)$

\section{CASH FLOWS FROM OPERATING ACTIVITIES}

After buying the necessary equipment, you turn your attention to operating activities. For the year, let the depreciation on the buildings be $\$ 5,000$ and $\$ 35,000$ on the equipment. Assume that these are the net amounts of depreciation after the sale of the buildings and equipment. The income statements for the XYZ Company for the year 2012 with and without the inclusion of the gain or loss on the sale of fixed assets are given in Table 2 . 
Table 2: Income Statements for the Year 2012 with and without the Inclusion of the Gain or Loss on the Sale of Fixed Assets

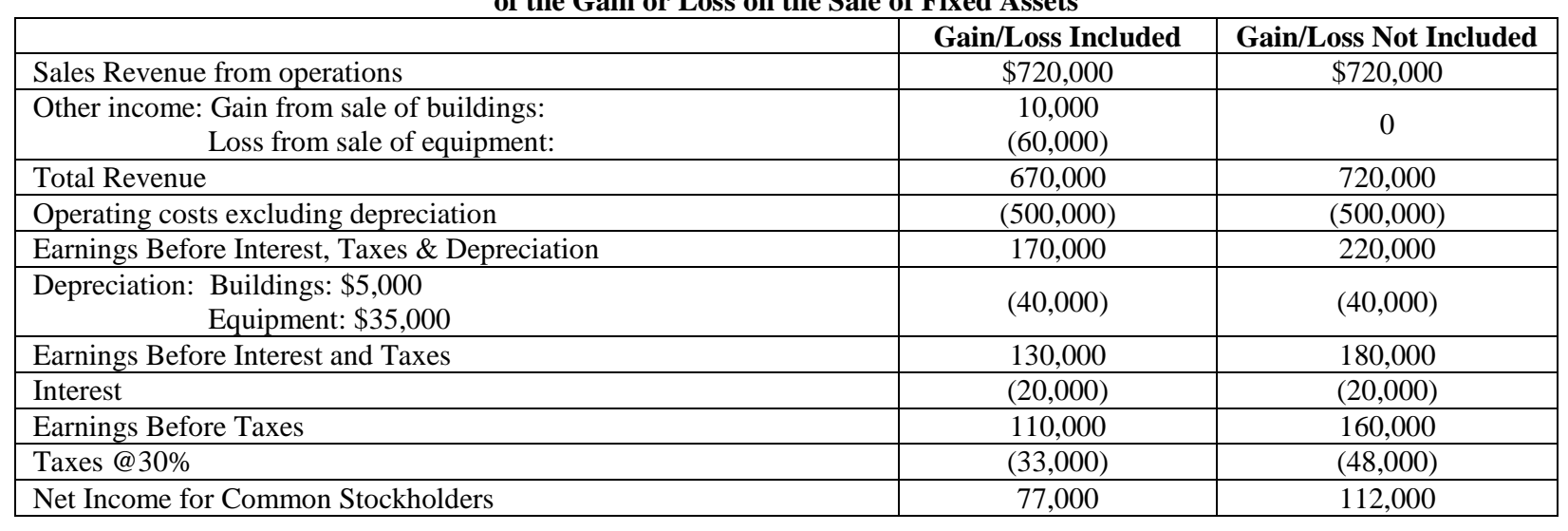

Comparing the two columns, you see that the net income from operations would have been much higher had the company not a suffered a significant loss from the sale of the equipment. However, the amount of taxes paid is also lowered by $\$ 15,000$ because of the loss. Of course, the tax rules require the company to calculate and pay the taxes on the total revenue regardless of how it was received. Also, the tax law allows the company to deduct the depreciation before the determination of taxes. The depreciation is called a non-cash charge because it was not paid to any outside organization, but kept within the company. In other words, the net result is that the company is left with an amount of $\$ 77,000$ in the form of net income and an additional amount of $\$ 40,000$ in the form of depreciation. However, the relevant question is, "How do you reconcile the figures from the two columns in assessing the net cash flows from just the operating activities?" Clearly, in enumerating the cash flows from operating activities, you cannot include the gains or losses from the sale of fixed assets, such as land, buildings or equipment, since they fall under the category of investing activities. In other words, you must make corrections or adjustments to the net income of $\$ 77,000$ in Table 2 by reversing the entries related to the sale of fixed assets. You have to reduce the net income by the amount of the gain on the sale of a fixed asset and increase the net income by the amount of the loss from the sale of the fixed asset. From an algebraic point of view, the gain will be treated as a loss and the loss as a gain. It may be noted that these gains and losses are already included in the cash flows from investing activities. Many students find this reversal of entries counter-intuitive and confusing when the cash flows from operating activities are enumerated before the cash flows from the investing activities. However, when the cash flows from investing activities are described before the operating activities, the confusion is cleared (or at least lessened) and the students can immediately see the need for the reversal of the entries related to the gains and losses on the sale of fixed assets. The part of the cash flow statement that reflects the effects of these reversals is:

Cash Flows from Operating Activities - Part A:

Net Income

Depreciation on buildings

Depreciation on Equipment

Gain from the sale of the buildings:

Loss from the sale of the equipment:

Adjustments related to fixed assets (effect of reversals)

Cash flows provided by Part A of operating activities
$\$ 77,000$

$\$ 5,000$

35,000

(10,000)

$\underline{60,000}$

$\underline{90,000}$

$\$ 167,000$

As a result of the operations, obviously there would be changes in current assets and current liabilities. Suppose the XYZ Company bought materials worth $\$ 30,000$ and paid cash for the whole purchase. Also, assume that the inventory of finished goods worth $\$ 20,000$ is sold at cost, with no profit margin, to a (very big) customer on credit. Clearly, the net effect is that a decrease of $\$ 30,000$ in $\mathrm{C}$ has resulted in an increase of $\$ 10,000$ in $\mathrm{V}$ and an increase of $\$ 20,000$ in $\mathrm{R}$. The point to be noted is that the variables $\mathrm{C}, \mathrm{R}$, and $\mathrm{V}$ are on the same side of Equation (2) and a decrease in one variable will lead to an increase in another variable or vice versa. In other words, the changes in $\mathrm{R}$ and $\mathrm{V}$ have an opposite effect on $\mathrm{C}$. Instead of paying cash, suppose that the company bought $\$ 30,000$ worth of Copyright by author(s); CC-BY 
materials on credit. Then, both the variables $\mathrm{P}$ and $\mathrm{V}$ will initially go up by $\$ 30,000$; subsequently, $\mathrm{V}$ will be down by $\$ 20,000$ and $R$ up by $\$ 20,000$ on the sale of finished goods at cost. Finally, when the company receives cash from one of the accounts receivable, $\mathrm{R}$ will go down and $\mathrm{C}$ will go up by the amount of cash received. In contrast, when the company pays cash to one of the accounts payable, both $\mathrm{C}$ and $\mathrm{P}$ will decrease by the same amount. Focusing on just the pair $\mathrm{P}$ and $\mathrm{C}$, one can conclude that an increase in $\mathrm{P}$ will ultimately lead to an increase in $\mathrm{C}$ and, similarly, a decrease in $\mathrm{P}$ to a decrease in $\mathrm{C}$, or any change in $\mathrm{P}$, will lead to a similar change in $\mathrm{C}$.

From these examples, one can conclude that there are many interdependent changes. One scenario is that an increase in a current asset (such as Accounts Receivable or Inventories) will lead to a decrease in the cash position, and vice versa if the transactions are limited to the LHS. Another scenario is that an increase or decrease in a current liability (such as Accounts Payable) will ultimately lead to a similar change in the cash position through a sequence of transactions. In other words, two simple rules in preparing the SCF are: (a) reverse the sign of changes in current assets and (b) keep the same sign for the changes in current liabilities, in assessing their impact on the net cash position. These simple rules will be adequate in preparing the Statement of Cash Flows. Suppose that as a result of all the transactions during the year, the values of the variables at the end of the year 2012 are: Accounts Receivable $\mathrm{R}=68,000$, Inventories $-\mathrm{V}=23,000$, and Accounts Payable $-\mathrm{P}=64,000$. Then the changes (denoted by the algebraic symbol $\Delta$ ) in the different variables are: $\Delta \mathrm{R}=68,000-59,000=9,000, \Delta \mathrm{V}=23,000-28,000=-5000$, and $\Delta \mathrm{P}=64,000-57,000=7,000$. The impact of these changes on the cash position is shown below. This is part $\mathrm{B}$ of the cash flows from operating activities.

Cash Flows from Operating Activities - Part B:

Changes in Current Assets and Current Liabilities

Increase in Accounts Receivable (opposite effect on cash)

$(\$ 9,000)$

Decrease in Inventories (opposite effect on cash)

5,000

Increase in Accounts Payable (same effect on cash)

$\underline{7,000}$

Net effect of changes in current assets and current liabilities

3,000

Net cash generated by operating activities $($ Part A + Part B $)=167000+3000=$

170,000

\section{CASH FLOWS FROM FINANCING ACTIVITIES}

When the company issued new common stock worth $\$ 100,000$ at the beginning of the year, obviously the value of $\mathrm{S}$ would rise to $\$ 418,000$ and the amount of cash would also go up by $\$ 100,000$. Further, an amount of $\$ 130,000$ was added to the cash from the sale of buildings and equipment and new equipment worth $\$ 220,000$ was also purchased. At the end of the year, the net cash flow from operations was $\$ 170,000$. Suppose the company then redeemed bonds worth $\$ 120,000$ and paid dividends of $\$ 34,000$ to the stockholders. In mathematical terms, it can be described in a simple way - the value of one RHS variable S (common stock) was increased by $\$ 100,000$ which, in turn, temporarily increased the value of one LHS variable C (cash) by $\$ 100,000$. Subsequent selling of buildings and equipment increased the level of cash by only $\$ 130,000$, though the total book value of the fixed assets sold was $\$ 180,000$. The difference of $\$ 50,000$ was recovered from operations later. When new equipment was bought for $\$ 220,000$, the value of the variable C (cash) was immediately reduced by an equal amount. When bonds are redeemed or dividends are paid out, the value of $\mathrm{C}$ goes down by the same amount. In other words, one change on one side can lead to several changes on both sides of the equation. In general, when a variable on the RHS goes up, another variable - most often the cash (C) - goes up on the LHS; then, the cash is used to buy an asset (i.e., increase the value of a variable on LHS) or reduce the value of a liability (i.e., a variable on RHS). Since the net income for the year is $\$ 77,000$, an amount of $\$ 43,000$ would be added to $\mathrm{T}$ (retained earnings) at the end of the year, after the dividends of $\$ 34,000$ are paid out. At this point, the cash flows from financing activities can be enumerated as:

Cash Flows from Financing Activities:

Redemption of bonds (or paying back long-term debt)

$(\$ 120,000)$

Issue of common stock

100,000

Payment of dividends

$\underline{(34,000)}$

Net cash flow generated by financing activities:

$(54,000)$ 
With all these changes, what would be the values of the assets and liabilities at the end of the year?

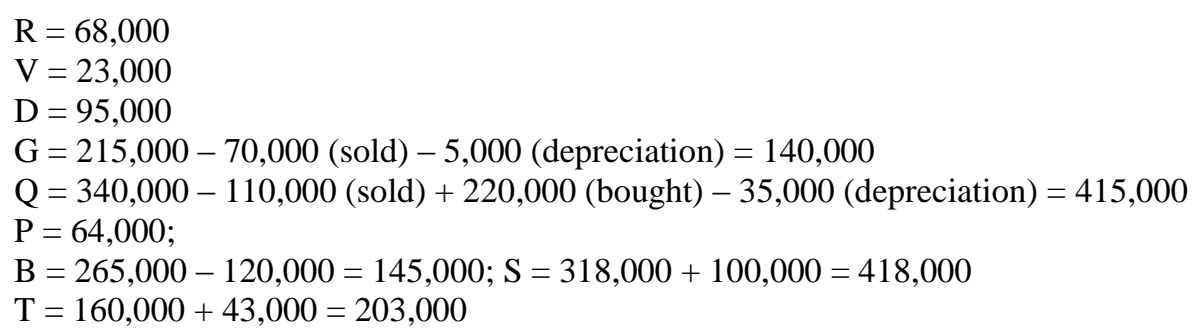

Net cash flow from Investing, Operating and Financing Activities $=-90,000+170,000-54,000=26,000$.

Therefore, at the end of the year, the amount of cash $C=63,000+26,000=89,000$.

Sum of LHS variables $=\mathrm{C}+\mathrm{R}+\mathrm{V}+\mathrm{D}+\mathrm{G}+\mathrm{Q}=89,000+68,000+23,000+95,000+140,000+415,000=$ 830,000

Sum of RHS variables $=\mathrm{P}+\mathrm{B}+\mathrm{S}+\mathrm{T}=64,000+145,000+418,000+203,000=830,000$

Clearly, at the end of the year, the total assets are equal to $\$ 830,000$ and total liabilities also equal $\$ 830,000$, as it should be. If the values of the variables C, R,V, D, G, and Q on the LHS and P, B, S, and T on RHS are displayed in the form of another Table (as in Table 1), that table would be nothing but the balance sheet at the end of the year 2012.

\section{SUMMARY}

In this paper, the link between the accounting equation of the balance sheet and the algebraic foundations of the SCF are discussed. The item-by-item enumeration rules described in the standard textbooks for preparing the SCF are reduced to two simple rules: (a) Reverse the sign of the change in a currents asset and (b) keep the same sign for the change in a current liability in evaluating their effect on the net cash position. Further, an example is provided to clarify the reversal of the entries related to the gain or loss on the sale of fixed assets in preparing the SCF.

\section{AUTHOR INFORMATION}

Donald T. Joyner is an assistant professor of Accounting in the School of Business at Norfolk State University. E-mail: dtjoyner@nsu.edu (Corresponding author)

Jean-Marie Banatte is a professor of Accounting in the School of Business at Norfolk State University. E-mail: banatte@cox.net

V. Reddy Dondeti is a professor of Decision Sciences in the School of Business at Norfolk State University. E-mail: vrdondeti@nsu.edu

\section{REFERENCES}

1. Cecil, H. W., King, T. T., \& Andrews, C. P. (2011). Back to basics: Teaching the statement of cash flows. American Journal of Business Education, 4(2), 41-46.

2. Chen, J., \& Dondeti, V. R. (2000). An algebraic interpretation of cash flow statements. Proceedings of the 36th Annual Meeting (on CD-ROM), Southeast INFORMS. (pp. 74-77).

3. Chen, J., Dondeti, V. R., \& Zemedkun, W. (2009). Preparation of cash flow statement: An algebraicaccounting equation approach for classroom instruction. Review of Business Research, 9(2), 117-126. 
4. Kieso, D. E., Weygandt, J. J., \& Warfield, T. D. (2012). Intermediate accounting (14 ${ }^{\text {th }}$ Ed.). Hoboken, NJ: John Wiley \& Sons.

5. Laux, J. (2009). Accounting issues: An essay series part IX - statement of cash flows. Journal of College Teaching \& Learning, 6(3), 17-24.

6. O’Bryan, D., Berry, K. T., Troutman, C., \& Quirin, J. J. (2000). Using accounting analysis to teach the statement of cash flows in the first financial accounting course. Journal of Accounting_Education, 18(2), 147-155.

7. Rai, A. (2003). Reconciliation of net income to cash flow from operations: An accounting equation approach. Journal of Accounting Education, 21(1), 17-24.

8. Wang, T. J. (2010). A conceptual framework for the indirect method of reporting net cash flow from operating activities. American Journal of Business Education, 3(12), 19-32. 